3 Cripps T, Bennett ED, Camm AJ, Ward DE. Inducibility of sustained monomorphic ventricular tachycardia as a prognostic indicator in survivors of recent myocardial infarction: a prospective evaluation in relation to other prognostic variables. $\mathrm{J} \mathrm{Am} \mathrm{Coll}$ Cardiol 1989;14:289-96.

4 Richards D, Cody D, Denniss A, Russell P, Young A, Uther J. Ventricular electrical instability: a predictor of death after myocardial infarction. Am J Cardiol 1983;51:75-80.

5 Waspe E, Seinfeld D, Kim SG, Matos JA, Fisher JD. Prediction of sudden death and spontaneous ventricular tachycardia in survivors of uncomplicated myocardial infarction: value of the response to programmed stimulation using a maximum of three ventricular extrastimuli. J Am Coll Cardiol 1985; 5:1292-301.

This letter was shown to the authors, who reply as follows:

Sir,

As Dr Cripps and his colleagues note (and as we emphasised in our article) the results of our study are applicable only to clinically stable patients with uncomplicated myocardial infarctions and the finding ought not be extrapolated to patients with complicated infarctions where the risk of future arrhythmic events is higher and the predictive accuracy of programmed ventricular stimulation may be better. Their study ${ }^{1}$ and others including our own, ${ }^{2-4}$ support the clinical use of programmed ventricular stimulation in such patients.

Until recently there were few data on the clinical significance of inducible ventricular fibrillation in survivors of acute myocardial infarction. The results of our study and those of Denniss et $\mathrm{al}^{3}$ clearly show that inducible ventricular fibrillation is a nonspecific response of little clinical significance in these patients. Therefore we agree that this arrhythmia should not be included as a positive end point in existing or future prospective trials of programmed

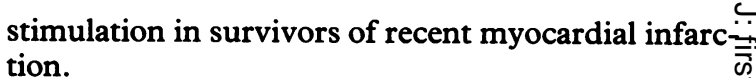

In our article we commented on the limitation imposed by the empirical antiarrhythmic treatmen started in our first 10 patients with inducible sus $\frac{\bar{\omega}}{\vec{S}}$ tained ventricular arrhythmias. The minimum length of follow up was at least 12 months in all bue five patients, who were lost to follow up between four and eight months after the index infarction.

\section{A K Bhandari}

Los Angeles Cardiology Associates,

1245 Wilshire Boulevard,

Suite 606,

Los Angeles, CA 90017,

USA

\section{References}

1 Cripps TR, Bennett ED, Camm AJ, Ward DE. Inducibility of sustained monomorphic ventricular tachycardia as a prognostic indicator in survivors of $\stackrel{\Phi}{-}$ recent myocardial infarction: A prospective evalu- $\vec{\theta}$ ation in relation to other variables. J Am Coll Cardiol $\varnothing$ 1989;14:289-96.

2 Waspe LE, Seinfeld D, Ferrer A, et al. Prediction of $\square$ sudden death and spontaneous ventricular tachy- $\sum$ cardia in survivors of complicated myocardial infarction: Value of the response to programmed stimulation using a maximum of three ventricular extrastimuli. J Am Coll Cardiol 1985;5:1292-301.

3 Denniss AR, Richarde DA, Cody DV, et al. Prognostic $\overrightarrow{\vec{O}}$ significance of ventricular tachycardia and fibrillation $\exists$ induced at programmed stimulation and delayed $\supset$ potentials detected on the signal averaged electro- cardiograms of survivors of acute myocardial infarction. Circulation 1985;74:731-45.

4 Bhandari A, Hong R, Kotlewski A, Rubin J, McIntosh N, Rahimtoola SH. Prognostic significance of pro- $\bar{\sigma}$ grammed stimulation in high risk patients surviving acute myocardial infarction [Abstract]. $\mathrm{J} \mathrm{Am} \mathrm{Coll}$ \% Cardiol 1988;11:6.

\title{
Timing of treatment with oxygen radical scavengers and its influence on reperfusion injury
}

Sir,

In their editorial on oxygen radicals and myocardial damage (1989;61:4-8), Burrell and Blake pointed out that proof that there is specific, reperfusion-mediated damage depends on the administration of oxygen radical scavengers at the moment of reperfusion rather than before the onset of ischaemia. This is a valid point, but the reader may be left with the impression that the hypothesis of a specific reflow injury remains to be tested because the editorial does not refer to the results of several pertinent published reports.

In the classic study by Jolly et al, administration of

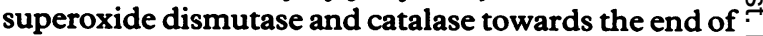
the ischaemic period proved as effective in reducing infarct size as pretreatment. ${ }^{1}$ Furthermore, in other $\frac{\vec{D}}{\mathbb{D}}$ studies administration of "anti-free radical" agents $\stackrel{\odot}{\odot}$ at the moment of reflow, after the ischaemic episode, 
considerably reduced the myocardial concentration of oxygen radicals, ${ }^{2}$ improved recovery of energy metabolism ${ }^{34}$ and of contractile function in isolated hearts ${ }^{34}$ and in anaesthetised dogs, ${ }^{5}$ and reduced infarct size in a long term canine model of coronary artery occlusion and reperfusion. ${ }^{6}$

Thus although the issue is not yet settled, ${ }^{7-9}$ there seems to be substantial evidence to indicate that, under certain circumstances, oxygen radicals can induce specific myocardial damage, which is separate from ischaemic damage, in various experimental models of post-ischaemic reperfusion. The studies that I draw attention to go some way to proving that scavengers of oxygen radicals given at the moment of reperfusion are effective in countering this specific myocardial damage.

Giuseppe Ambrosio, Division of Cardiology, 2nd School of Medicine, University of Naples, Via Sergio Pansini 5, 80131 Naples,

Italy.

\section{References}

1 Jolly SR, Kane WJ, Bailie MB, Abrams GD, Lucchesi BR. Canine myocardial reperfusion injury. Its reduction by the combined administration of superoxide dismutase and catalase. Circ Res 1984;54:277-85.

2 Zweier JL, Rayburn BK, Flaherty JT, Weisfeldt ML. Recombinant superoxide dismutase reduces oxygen free radical concentrations in reperfused myocardium. J Clin Invest 1987;80:1728-34.

3 Ambrosio G, Weisfeldt ML, Jacobus WE, Flaherty JT. Evidence for a reversible oxygen radical-mediated component of reperfusion injury: reduction by recombinant human superoxide dismutase administered at the time of reflow. Circulation 1987;75:282-91.

4 Ambrosio G, Zweier JL, Jacobus WE, Weisfeldt ML, Flaherty JT. Improvement of post-ischaemic myocardial function and metabolism by administration of deferoxamine at the time of reflow: the role of iron in the pathogenesis of reperfusion injury. Circulation 1987;76:906-15.

5 Bolli R, Patel BS, Jeroudi MO, Lai EK, McCay PB. Demonstration of free radical generation in "stunned" myocardium of intact dogs with the use of the spin trap alpha-phenyl N-tert-butyl nitrone. J Clin Invest 1988; 88:476-85.

6 Ambrosio G, Becker LC, Hutchins GM, Weisman HF, Weisfeldt ML. Reduction in experimental infarct size by recombinant human superoxide dismutase: insights into the pathophysiology of reperfusion injury. Circulation 1986;74:1424-33.

7 Richards VJ, Murry CE, Jennings RB, Reimer KA. Therapy to reduce free radicals during early reperfusion does not limit the size of myocardial infarcts caused by $90 \mathrm{~min}$ of ischemia in dogs. Circulation 1988;78:473-80.

8 Przyklenk K, Kloner RA. "Reperfusion injury" by oxygen free radicals? Effect of superoxide dismutase plus catalase, given at the time of reperfusion, on myocardial infarct size, contractile function, coronary microvasculature, and regional myocardial blood flow. Circ Res 1989;64:86-96.

9 Nejima J, Knight DR, Fallon JT, et al. Superoxide dismutase reduces reperfusion arrhythmias but fails to salvage regional function or myocardium at risk in conscious dogs. Circulation 1989;79:143-53.

This letter was shown to the authors, who reply as follows:

Sir,

The results of many studies confirm the occurrence of a reperfusion event associated with the formation of oxygen free radicals in animals. ${ }^{1}$ There is similarly convincing evidence that in the animal heart this event is associated with myocardial injury and that the extent of this injury may be modified by agents altering free radical mechanisms. ${ }^{2}$ The optimal timing for such therapeutic intervention remains open to debate, but certainly some benefit may be achieved from treatment given after the ischaemic period.

However, small animals may be particularly susceptible to oxidative stress, ${ }^{34}$ and therefore more likely to benefit from antioxidant treatment, and the applicability of animal studies to patients with acute myocardial infarction is in some doubt.

From a practical point of view, long term prophylactic treatment for patients at risk of infarction with agents such as allopurinol seems unlikely to become widely established even if a small benefit were shown, and the potential beneficial effects of free radicals ${ }^{5}$ may be jeopardised by such treatment. An "anti-free radical" cocktail administered at the same time as a thrombolytic agent (that is after the ischaemic period, immediately before reperfusion) is the most promising starting point, and we agree with Ambrosio that any evidence that this may be beneficial in animals ${ }^{67}$ is encouraging. However, this does not alter our conclusion that therapeutic trials are not justified without further elucidation of free radical interactions in humans $(1989 ; 61: 4-8)$.
C J Burrell,
D R Blake,
Cardiac Department,
The London Hospital,
Whitechapel,
London E1 1BB. 